\title{
Article
}

\section{Triangulation and the importance of establishing valid methods for food safety culture evaluation}

Jespersen, Lone and Wallace, Carol Anne

Available at http://clok.uclan.ac.uk/19298/

Jespersen, Lone and Wallace, Carol Anne ORCID: 0000-0002-1402-2134 (2017) Triangulation and the importance of establishing valid methods for food safety culture evaluation. Food Research International, 100 (1). pp. 244253. ISSN 0963-9969

It is advisable to refer to the publisher's version if you intend to cite from the work. http://dx.doi.org/10.1016/j.foodres.2017.07.009

For more information about UCLan's research in this area go to http://www.uclan.ac.uk/researchgroups/ and search for <name of research Group>.

For information about Research generally at UCLan please go to http://www.uclan.ac.uk/research/

All outputs in CLoK are protected by Intellectual Property Rights law, including Copyright law. Copyright, IPR and Moral Rights for the works on this site are retained by the individual authors and/or other copyright owners. Terms and conditions for use of this material are defined in the policies page.

\section{CLoK}

Central Lancashire online Knowledge www.clok.uclan.ac.uk

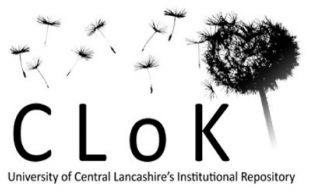




\section{Triangulation and the importance of establishing valid methods for food safety culture evaluation}

Lone Jespersen, University of Guelph (1 and Prof. Carol A Wallace, University of Central Lancashire (2).

5 (1) University of Guelph, Department of Food Science, 50 Stone Road East, Guelph, ON N1G 2M7, Canada

(2) University of Central Lancashire, International Institute of Nutritional Sciences and Applied Food Safety Studies, Preston, Lancashire PR1 2HE, United Kingdom.

\section{Corresponding author}

10 Lone Jespersen, University of Guelph, Department of Food Science, 50 Stone Road East,

11 Guelph, ON, N1G 2M7, Canada. +41792460807. lone@uoguelph.ca

\section{Abstract}

The research evaluates maturity of food safety culture in five multi-national food

14 companies using method triangulation, specifically self-assessment scale, performance

15 documents, and semi-structured interviews. Weaknesses associated with each individual method

16 are known but there are few studies in food safety where a method triangulation approach is used

17 for both data collection and data analysis. Significantly, this research shows that individual

18 results taken in isolation can lead to wrong conclusions, resulting in potentially failing tactics

19 and wasted investments. However, by applying method triangulation and reviewing results from 
20 a range of culture measurement tools it is possible to better direct investments and interventions.

21 The findings add to the food safety culture paradigm beyond a single evaluation of food safety

22 culture using generic culture surveys.

\section{Keywords}

25 Method triangulation, food safety culture evaluation, maturity profiling culture scale, 26 content analysis, semi-structured interview.

\section{Highlights}

29 - Establishes importance of triangulation for valid food safety culture evaluation

30 - Compares data from scale, performance documents, and semi-structured interviews

31 - Confirms need for multiple methods for trustworthy evaluation of food safety culture

32 - Applies culture coding framework to interview transcripts and performance documents

33 - Inter-coder and construct validity, and discrimination in food safety culture profiles

\section{$36 \quad 1.0$ Introduction}

37 The understanding of culture to enable organizational effectiveness has been studied at

38 length since 1970 and before. (Hofstede, 1980, 2001, 2013) studied national culture through his

39 cross-cultural organizational studies research, starting with the international (IBM) survey in

40 1966, and showed predictive validity of his 'Values Survey Module' instrument to dimensions of

41 national culture. D. R. Denison (1997) developed a model for corporate culture and 
42 organizational effectiveness through his research on organizational culture evaluation methods

43 with predictive validity of two measures of organizational effectiveness: behavioral data and

44 financial data (D. Denison, Hooijberg, Lane, \& Lief, 2012; D. R. Denison, 1997; D. R. Denison

$45 \&$ Mishra, 1995). These types of evaluations appeal to leaders in organizations as they quantify

46 areas of strength and weakness in an accessible and validated form. Culture researchers, in all

47 domains, must take seriously these lessons from early front-runners, like Hofstede and Denison,

48 to understand the dichotomy of fulfilling leaders needs for aggregated, leading indicators of

49 culture change progress and developing meaningful and trustworthy measurement tools.

50 (Guldenmund, 2000) discusses this dichotomy specific to the people safety culture domain. He

51 postulates that assumptions are often made that organizations are homogeneous and can be

52 evaluated using an organization-wide, generic questionnaire survey but that this approach can be

53 risky and virtually meaningless as organizations are highly heterogeneous and made up of formal

54 and informal working groups (Guldenmund, 2000). This suggests that other approaches are

55 needed to understand the heterogeneity of organizations which are typically made up of sub-

56 groups and macro-cultures (Schein \& Schein, 2017).

\subsection{Theoretical framework}

To link the food safety domain with existing models for organizational culture, safety

59 climate/culture, and food safety climate/culture, Jespersen et al (2017) developed a theoretical

60 framework based on eight existing cultural evaluation models (Ball, Wilcock, \& Aung, 2009; De

61 Boeck, Jacxsens, Bollaerts, Uyttendaele, \& Vlerick, 2016; De Boeck, Mortier, Jacxsens,

62 Dequidt, \& Vlerick, 2017; Denison et al., 2012; Denison, 1997; Denison \& Mishra, 1995;

63 Jespersen, Griffiths, Maclaurin, Chapman, \& Wallace, 2016; Srinivasan \& Kurey, 2014; Taylor, 
64 2015; Wilcock, Ball, \& Fajumo, 2011; Wright, 2013). The framework was developed through

65 content analysis of eight culture or food safety culture evaluation systems. Each of the systems

66 had been applied to evaluate culture in food companies by applying mostly self-assessment

67 surveys. Content analysis was completed in NVivo 11 [Computer Software] QSR International,

68 Doncaster, Australia] by importing textual material into NVivo and coding content to nodes

69 deduced from literature review. The researchers deduced the dimensions from the coded material

70 by comparing the details of the specific dimensions from each system. Although these had been

71 named differently by each author, i.e., dimensions, traits, capability areas, categories, elements,

72 Jespersen et al (2017) aligned the descriptors in this framework under the title "dimensions."

73 Together the five dimensions (Figure 1) encompass all the individual dimensions in the eight

74 culture evaluation systems, although none of the eight systems covers all five dimensions. The

75 framework (Jespersen et al, 2017) was the first work to compare and contrast culture evaluation

76 systems with the goal of developing one theoretical framework. Its development is an attempt to

77 bring consensus to the theory of food safety culture and the framework has been applied by the

78 Global Food Safety Initiative (GFSI) in its work to provide guidance to its stakeholders on food

79 safety culture (pers. comm. Robach $\left.{ }^{1}, 2016\right)$.

\footnotetext{
${ }^{1}$ Mike Robach, Chair of Global Food Safety Initiative Board.
} 


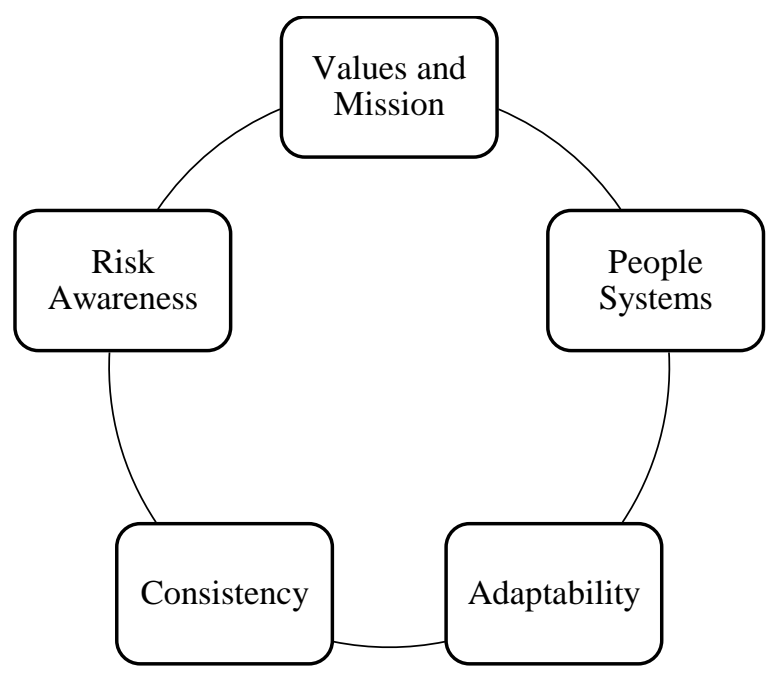

Figure 1: Food safety culture - dimensional framework (Jespersen, Griffiths, 82 and Wallace, 2017)

\subsection{Food safety culture evaluation systems}

85 culture evaluation system results to assess their validity and reliabililty and this is particularly

86 important where cultural evaluation is being used as part of consumer protection measures in the

87 food safety domain. However, current systems for evaluating culture are fragmented and built on

88 disparate scientific theories (De Boeck, Jacxsens, Bollaerts, \& Vlerick, 2015; Guldenmund,

89 2000), and many make use of single evaluation methods, e.g. a self-assessment scale or audit

90 (Jespersen et al, 2017), an approach not without its limitations (Guldenmund, 2000). Thus it is

91 important to consider whether food safety culture evaluation systems could be strengthened by

92 extension with additional evaluation methods and whether this can give richer information about

93 the heterogeneious organisations in the global food supply chain. 
Triangulation has for more than 75 years been an accepted method to confirm that the

96 variance of a phenomenon is tested and not the variance of the method(s) used (Campbell, 1959;

97 Denzin, 1970; Denzin, 2012; Miles, 1994). These and other authors have defined six types of

98 triangulation including the one applied in this research - method triangulation. Method

99 triangulation means to gather information pertaining to the same phenomenon through more

100 than one method, primarily to determine if there is a convergence and hence, increased validity

101 in the findings (Carugi, 2016; Kopinak, 1999). Triangulation enables examination of similarities

102 and discrepancies in a research topic, and the assessment of socially desirable responding in

103 sensitive and complex topics (Bauwens, 2010). In addition, it allows researchers to strive for

104 completeness and confirmation of research findings (Yeasmin \& Rahman, 2012) as weaknesses

105 in one method can be counterbalanced by the strength in others (Carugi, 2016; Kopinak, 1999).

106 Given both the inner and outer influences that can significantly influence the strength of

107 organizational and -food safety culture, as in other social science domains e.g., health (Carugi,

108 2016; Kopinak, 1999), it is reasonable to assume that combining or triangulating methods in the

109 investigation process can provide a more comprehensive evaluation of cultural strength. Social

110 realities, such as those existing in organizational and food safety cultures, are inherently complex

111 and therefor difficult to evaluate with one method (Yeasmin \& Rahman, 2012). Triangulation

112 can lead to an elaboration and enrichment of findings e.g., by providing more detail, multilayered

113 and multi-dimensional perspectives of the phenomenon being studied (Carugi, 2016; Kopinak,

114 1999) and increase credibility of scientific knowledge by improving both internal consistency

115 and generalizability (Yeasmin \& Rahman, 2012). Quoting McKinlay (1992), "rigid adherence to 
116 one approach at the expense or to the exclusion of the other, is destructively parochial and results

117 in often incomplete or even inaccurate explanations and by extension, wrongly focused research.

118 In the data analysis phase triangulation offers several benefits: verification of overlapping

119 results, validation of quantitatively generated constructs through comparison, opportunity to

120 probe and investigate potential causes of discrepancies due to instruments or misrepresentation

121 of data, and clarity of ambiguous and provocative replies or questions (Floyd, 1993). There are

122 difficulties related to the application of method triangulation. There must be consistent and clear

123 foci between the different methods and, in advance of the research, the researcher must have

124 clear prior understanding of the main ontological and epistemological position of the

125 phenomenon under investigation without which the findings and conclusions might be

126 meaningless (Norman K Denzin \& Lincoln, 2011). Also, triangulation is time consuming and

127 will increase the time needed to complete a study; however, the authors would argue that this

128 approach is essential in establishment of new evaluation methods. Lastly triangulation is carried

129 out with complex research designs and there are limited guidelines available to researchers as for

130 how to meaningfully combine different data types, interpret divergent results, decide what to do

131 with overlapping concepts, and how to weigh different sources of information (Carugi, 2016;

132 Kopinak, 1999). Further literature discussion would be beneficial to overcome gaps in guidance;

133 however, discussion of potential approaches with other researchers to reach consensus in

134 triangulation plans would seem to be a good way forward and was applied in this research. The

135 objective of this research was to develop and apply method triangulation to increase validity of 136 food safety culture evaluation results. 


\subsection{Materials and methods}

138 This research was part of a large study of food safety culture performance conducted in

139 collaboration with five multi-national North American-based food manufacturing companies

140 from October 2015 to March 2016. The five companies volunteered to participate in the research

141 and provided the researcher access to total 21 plants. The companies varied in sizes from total

142 three manufacturing sites to over 100 per company. Products manufactured by the companies

143 varied as well from prepared meats, canned vegetables, milk power, and cheese. To reach

144 saturation in qualitative research there are various guidelines regarding sample sizes (Creswell,

145 1998; Denzin \& Lincoln, 2011). For this triangulation study, one plant from each company was

146 sampled and three data sets were collected from each plant (Table 1).

$147 \quad$ Table 1: Sources by plant and data type

\begin{tabular}{llllll}
\hline Plant ID & 1 & 2 & 3 & 4 & 5 \\
\hline Self-assessment responses & 63 & 14 & 10 & 15 & 71 \\
Performance documents & 5 & 1 & 6 & 5 & 3 \\
Semi-structured interviews & 2 & 2 & 2 & 2 & 2 \\
\hline
\end{tabular}

The authors believe this sample size to be large enough to obtain a result that could help

150 test the hypothesis that triangulation provides a more comprehensive evaluation of culture than

151 relying on a single method. Three data sets were; food safety culture maturity self-assessment

152 responses, food safety documents, and semi-structured interviews with plant leaders (Figure 2). 


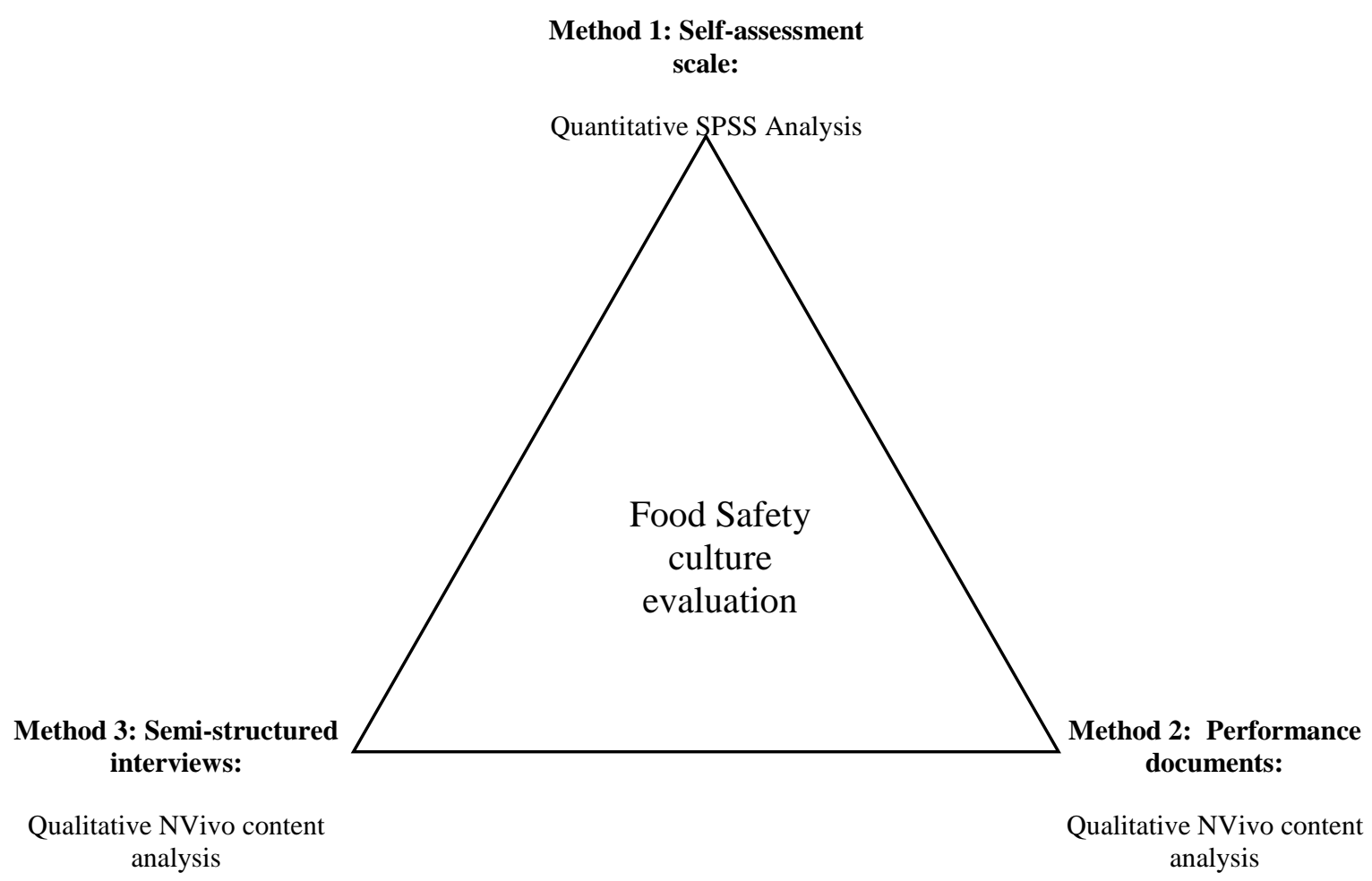

Each method was selected to provide as much data possible on the same phenomenon -

Figure 2: Methods and data triangulation applied to evaluate of food safety culture.

155 food safety culture - to counter weaknesses in each other method, to gain depth of

156 understanding and to make use of already existing data e.g., food safety documents.

\subsection{Methods strengths and weaknesses}

Three methods were selected for the study of triangulation (Figure 2). These three were

159 selected as they were believed to collectively minimize the method weaknesses of the individual

160 methods and provide complementary data from the plants under investigation based on the

161 strengths and practicalities of each. Strength and weaknesses of each of the three methods are 
162 discussed to illustrate how each method can mitigate weaknesses in others through method

163 triangulation. Method 1- Scale: The strengths of scales or survey are that they are simple and

164 straightforward methods for respondents to share knowledge, they provide generalizable

165 information, and maintain respondent anonymity. The weaknesses are that data are affected by

166 the characteristics of the respondents, there can be a gap between respondents' actual beliefs and

167 attitudes to the responses, low response rates that can make it difficult to know if the results are

168 representatives of all groups, and insincere responses can be hard to detect (Denzin, 1970;

169 Robson, 2011). Method 2 - Performance document content analysis: Strengths of content

170 analysis are data gathering is virtually unobtrusive, low cost, can be used non-reactively, and

171 data can relatively easy be generated for longitudinal analysis. The weaknesses of this method

172 are potential difficulty in locating content relevant to the research questions, that it is limited to

173 analyzing records and information that others have decided were worth preserving, and it is

174 ineffective for testing causality as such content analysis can be used to say what is present but

175 not why (Berg, 2012; Robson, 2011). Method 3 - Semi-structured interviews: Strengths of semi-

176 structured interviews are the ability to follow up on leads, providing a moving trail of

177 investigation based on the respondents answer. They are especially suitable for collecting data

178 of sensitive topics because of interviewers ability to investigate underlying motivations, and

179 capture non-verbal clues that can help better understand the verbal responses. The weaknesses

180 are quality of data is highly dependent on the skills and experience of the interviewer, internal

181 consistency can be difficult to demonstrate due to lack of standardization, interviews are time

182 consuming, it can be difficult to penetrate a groups language and mechanisms of symbolisms,

183 and there can be a resistance for the interviewee to "tell it all" (Berg, 2012; Brinkmann, 2015; 
184 Holstein, 1995; Robson, 2011). As such, the weaknesses of each method are countered by either

185 one or both the other methods. For example, survey and interviews can help assign causation,

186 survey can help mitigate impact of interviewer skill and experience, content can help penetrate

187 the group language and symbol mechanisms, content and survey can get data to close the attitude

188 to behaviour gap, survey social desirability and interviews can help identify insincere

189 respondents.

\subsection{Response analysis of self-assessment scale.}

191 All salaried staff in each manufacturing plant were invited to participate in an online

192 survey between November 2015 and March 2016. The survey invitation was sent via email with

193 a letter of invitation and purpose of the study for which the data were to be used. The participants

194 were also informed of the confidential nature of their individual responses and encouraged

195 through total three contact points (i.e., invitation, reminder, final reminder) to participate in the

196 study. The scale was developed by (Jespersen et al., 2016) and included questions pertaining to

197 four areas to measure food safety culture maturity; social norms, behavioral intent, motivation,

198 and social desirability. Response data were imported into SPSS [Computer Software] IBM

199 Corporation, New York, U.S.A. from Qualtrics [Computer Software] Qualtrics, Provo, Utah,

200 USA and readied (e.g., removal of incomplete data sets, reversal of negative scales) for analysis.

201 An aggregated maturity score (mean and standard deviation) as well as maturity level by

202 dimension (mean and standard deviation) were calculated for each plant with control for social

203 desirability score (Jespersen, Maclaurin \& Vlerick, 2017) amended with the findings from

204 (Jespersen \& Edwards, Under review)

Page 11 of 35 
The content analysis of food safety performance documents provides an insight into the

207 documented food safety culture e.g., level of consistency, adaptability, and perceived value of

208 food safety. Each of the manufacturing plants were asked to share food safety documents dating

209 back 12-months from November 2015. Food safety documents such as food safety audit reports,

210 food safety meeting minutes, inspection reports, and Good Manufacturing Practice (GMP)

211 records were obtained from each plant. Content analysis was applied to generate textual data

212 from these documents using a predefined coding framework deduced from literature review and

213 analysis of food safety culture and organizational culture evaluation tools. The coding

214 framework (Table 2) was defined using the theoretical framework (Figure 1) of food safety

215 culture and translated into nodes in NVivo [Computer Software] QSR International, Doncaster,

216 Australia. Sub-nodes were deduced through literature review and induced throughout the coding

217 process. Each document was imported into NVivo and all documents were coded by two

218 researchers.

\subsection{Content analysis of semi-structured interviews.}

Semi-structured interviews with senior plant leader and senior food safety leader were

221 arranged through the participating company sponsors. Invitation to the interview was sent via

222 email from the lead researcher and logistical detail arranged directly with the plant leader.

223 Interview questions were shared in advance with the interviewees and informed consent obtained

224 for each interview. All interviews were recorded and each audio file transcribed and codified to

225 ensure anonymity of the interview and uploaded to NVivo for content analysis. The same coding

226 framework was used for the interview files as the food safety documents (Table 2)

Page 12 of 35 
Table 2: Coding framework used in the content and textual analysis'. Adapted from Jespersen, Griffith, and Wallace (2017).

\begin{tabular}{|c|c|}
\hline Node & Sub-Nodes \\
\hline Values and Mission & $\begin{array}{l}\text { Compliance. } \\
\text { Measures/metrics/KPIs. } \\
\text { Mission, vision, goals. } \\
\text { Ownership/owning. } \\
\text { Plan/roadmap, direction. } \\
\text { Recall/recalls/withdrawals. } \\
\text { Responsibility, accountability, commitment. } \\
\text { Direction, setting expectations, corporate direction. } \\
\text { Financials, budgets, and prioritizing. }\end{array}$ \\
\hline People Systems & $\begin{array}{l}\text { Any reference to persons' role/education/job and group or team and references to individuals. } \\
\text { Behaviour/practice, work routine. } \\
\text { Communication and dialog. } \\
\text { Involvement. } \\
\text { Consequence, escalation. } \\
\text { Pride. } \\
\text { Rewards and celebration. } \\
\text { Training, education, learning, proficiency. } \\
\text { Cross-functional. } \\
\text { Unionized. } \\
\text { Rotation and retention. } \\
\text { "Making choices..." }\end{array}$ \\
\hline Consistency & $\begin{array}{l}\text { Actions, tasks, action due date. } \\
\text { Non-conformance, reoccurring. } \\
\text { Technology. } \\
\text { Tools, infrastructure, and policies/procedures. } \\
\text { References to third party standards. } \\
\text { Problems, breakdowns, and issues. }\end{array}$ \\
\hline Adaptability & $\begin{array}{l}\text { Change readiness, open to change, change ready. } \\
\text { Improvement, must improve, continuous improvement, improvement process, improvement } \\
\text { system, continuous improvement, Six Sigma, Lean manufacturing. }\end{array}$ \\
\hline Risks and Hazards & $\begin{array}{l}\text { Leaders risk awareness and perception. } \\
\text { Operator risk awareness and perception. } \\
\text { Risks, hazards. }\end{array}$ \\
\hline
\end{tabular}

\subsection{Content coding.}

232 (Wallace, 2009). The process for coding content (Figure 3) was used by two independent coders 
233 to ensure validity of data. The process consists of two checks for consistency evaluated through

234 calculation of percentage pairwise agreement. (Neuendorf, 2002) argues that the goal for

235 pairwise agreement in social sciences often are .8 but that .9 levels are most appropriate. This

236 higher threshold level has also been suggested to account for some weaknesses in this method

237 (Lombard, Snyder-Duch, \& Bracken, 2002). Based on these references the standard for this

238 research for pairwise agreement level was set to .9 (90\% agreement). Detailed research questions

239 were defined (step 1) and a coding framework was deduced (step 2) and translated into NVivo

240 nodes and sub-nodes (step 3). The framework was an important component as it connects the

241 coded data to the theoretical framework and the research domain. Following this, coders were

242 trained (step 4) and two documents coded by same coders (step 5). The results were analyzed by

243 detailed review of verbatim data to look for similarities and differences between coders. A

244 decision was made to go back to the coding framework and update with addition of sub-nodes

245 and to go back to the test documents for recoding (step 6). Following this loop, the decision was

246 made to carry on with the full document coding as coders were considered "consistent" based on

247 another detailed verbatim review (step 7). Midway discussions between coders allowed

248 comparison of experience, and discussion of coding difficulties and issues. These results led to

249 another rework of the two selected documents and finalization of the 30 documents (step 8).

250 Finally, the data was analyzed to derive information to answer the RQs (step 9). 
1. Define detailed research questions (RQ's)

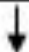

2. Develop coding framework

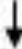

3. Translate into NVivo nodes and sub-nodes

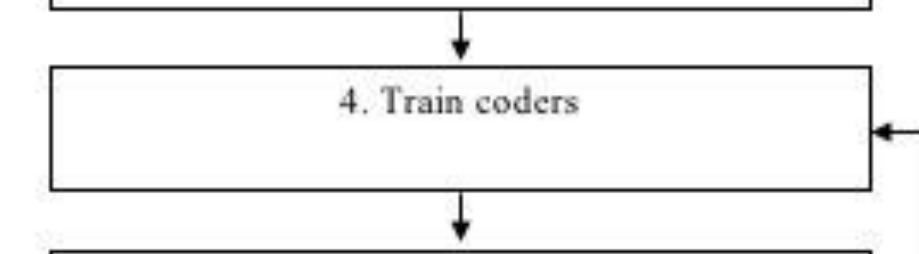

5. Multiple coders code same document
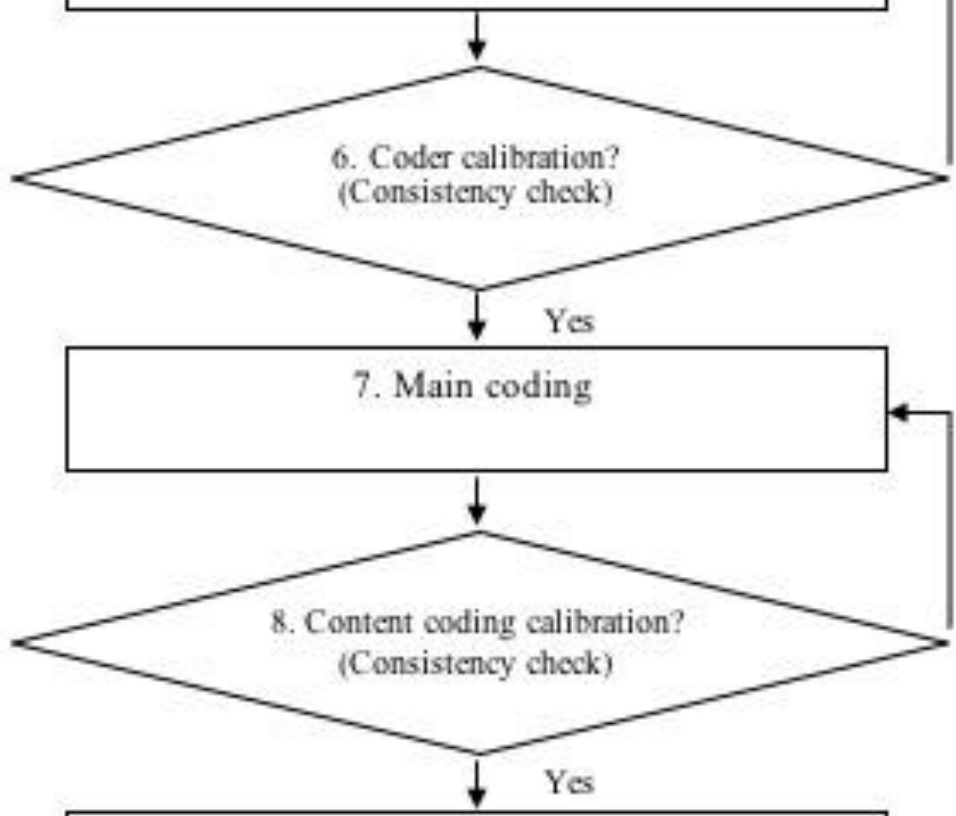

No

9. Derive information to answer RQ's

Figure 3: Coding process applied to deriving data through content analysis 


\subsection{Data triangulation.}

An updated version of the food safety maturity model (Jespersen et al., 2016) was used to

255 plot maturity by plant by cultural dimension based on the theoretical framework and scale

256 analysis (Jespersen and Edwards, 2017, under review). Three data points were plotted for each

257 plant, (1) quantitative results from the self-assessment scale were plotted directly on the model's

258 scale from stage one to stage five, (2) qualitative data based on the results from the file analysis

259 was grouped by plant by dimension and each cluster was plotted on the stage of maturity with

260 best fit to maturity model descriptors and behaviours, and (3) qualitative data based on the results

261 from the semi-structured interview analysis was grouped by plant by dimension and each group

262 was plotted on the stage of maturity with best fit to maturity model descriptors and behaviours.

263 By reviewing coded material for both (2) and (3) and comparing verbatim samples to the

264 definition of each maturity stage an individual score for (2) and (3) was assigned. For example,

265 “...yes, so we have some proactive and mainly reactive plethora of data, all manual...everything

266 is manual, right" this verbatim sample would be tagged as a stage 3 statement "knowing."

267 Taking another example, “...this company has never had a recall. I can't be the one that lets that

268 happen..." this verbatim sample would be tagged as a stage 2 "reactive" statement. In this way,

269 all codes were reviewed and placed in stage of maturity with best fit and an aggregated mean

270 score calculated from proportions of coded results in each stage. The triangulation allowed for

271 interpretation of findings for similarities, differences, identifying relationships, extracting

272 themes, and creating generalizations and to ensure that strengths and weaknesses of each method 273 were offset. 
$275 \quad 3.1$ Self-assessment results.

276 Differences in overall, aggregated maturity ratings through the self-assessment scale for

277 the five plants in the sub-set are not statistically significant for the overall maturity $F(4,182)$

$278=.273, p=.895$ (Table 3$)$.

279 Table 3: Sample size and mean maturity score from self-assessment scale. 280 Total and by individual dimension by plant. Lowest maturity score $=\mathbf{1}$; highest 281 maturity score $\mathbf{=}$.

\begin{tabular}{|c|c|c|c|c|c|}
\hline \multirow[b]{2}{*}{ Maturity } & \multicolumn{5}{|l|}{ Plant } \\
\hline & 1 & 2 & 3 & 4 & 5 \\
\hline $\begin{array}{l}\mathrm{N} \text { (Response } \\
\text { rate) }\end{array}$ & $63(82 \%)$ & $14(78 \%)$ & $10(43 \%)$ & $15(58 \%)$ & $71(41 \%)$ \\
\hline $\begin{array}{l}\text { Overall, } \\
\text { aggregated } \\
\text { score }\end{array}$ & 3.14 & 3.18 & 3.17 & 3.06 & 3.15 \\
\hline $\begin{array}{l}\text { Values and } \\
\text { Mission }\end{array}$ & 3.10 & 3.39 & 2.82 & 2.79 & 3.29 \\
\hline People & 3.41 & 3.41 & 3.46 & 3.44 & 3.29 \\
\hline Consistency & 2.93 & 2.76 & 3.22 & 2.97 & 2.87 \\
\hline
\end{tabular}

282

284 culture dimensional framework developed by assessing 8 culture evaluation systems (Jespersen

285 et al, 2017); however, these dimensions did not form part of the earlier Jespersen et al (2016)

286 tool and the subsequent evaluation scale which was tested through this research. As such, these

287 two dimensions could not be part of the method triangulation validation of the self-assessment 288 scale. 


\subsection{Coding comparisons.}

A comparison of Coders by dimension is shown in Figure 4. Total 4,522 references were 291 coded in 10 interview transcripts and 20 performance documents. Coders are considered similar

292 if within the set standard of $90 \%$ agreement. Agreement between coders was calculated for each

293 dimension and lowest level of pairwise agreement was calculated to $90.4 \%$. This result was

294 obtained after coding and recoding as per Figure 3. As such, content from two dimensions

295 needed to be recoded; Values and Mission and Risk Perception. The bar chart (Figure 4) shows

296 that coders are within $90 \%$ agreement on scoring except for Values and Mission (69\%

297 agreement) and Risk Awareness (79\% agreement).

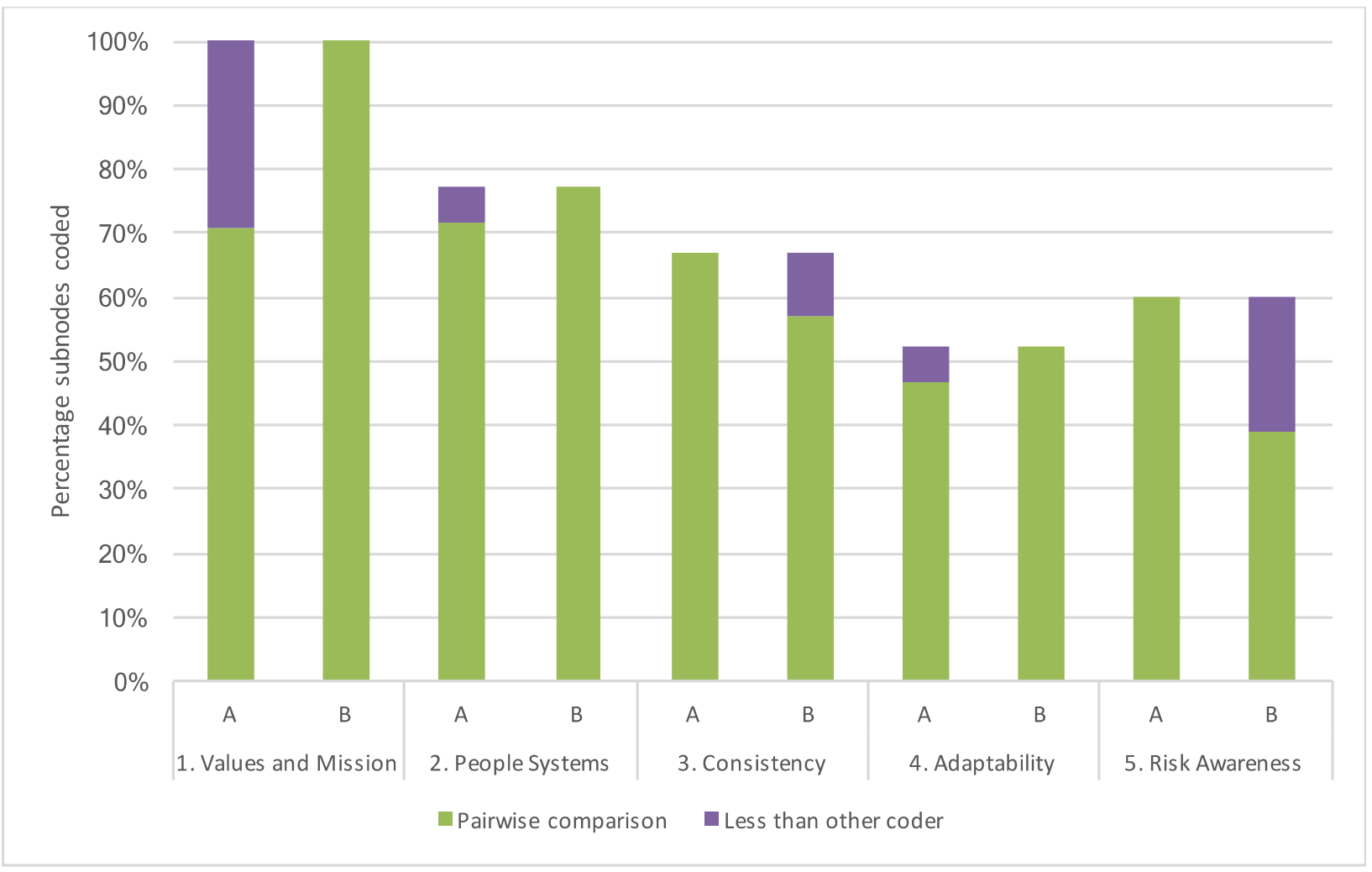




\section{Figure 4: Codes by dimension with pairwise comparison and difference by coder ( $A$ and $B=$ two different coders).}

In looking at the sub-nodes for Values and Mission (Figure 5) most of this difference

304 comes from differences in scoring of sub-nodes "Measures, metrics, and KPIs" and "Mission, 305 Vision, and Goals". Coder B coded 52.1\% more in the "Measures" than coder A and Coder A 306 coded 40.3\% more in "Mission" than Coder B. In addition, in "Recall, recalls, withdrawals"

307 Coder B coded 32.5\% more than Coder A, the sub-node "Measures", where verbatim data show

308 that Coder B coded any “metric” e.g., LM Product $0 \%$, whereas Coder A was looking for

309 measures taken to improve. Sub-node "Mission" verbatim shows that Coder A coded any

310 paragraph or statement leading to direction or priority of the organization. Coder A also included

311 any reference to "policy" which Coder B did not. Sub-node "Recall" verbatim show that Coder

312 A coded any paragraph with the word "recall" whereas Coder B coded paragraphs that indicate

313 recall as a potential outcome of a situation or environment. The differences between coders were

314 reviewed by both coders, discussed, and where needed, amendments were made to increase

315 clarity of application of the coding framework. 


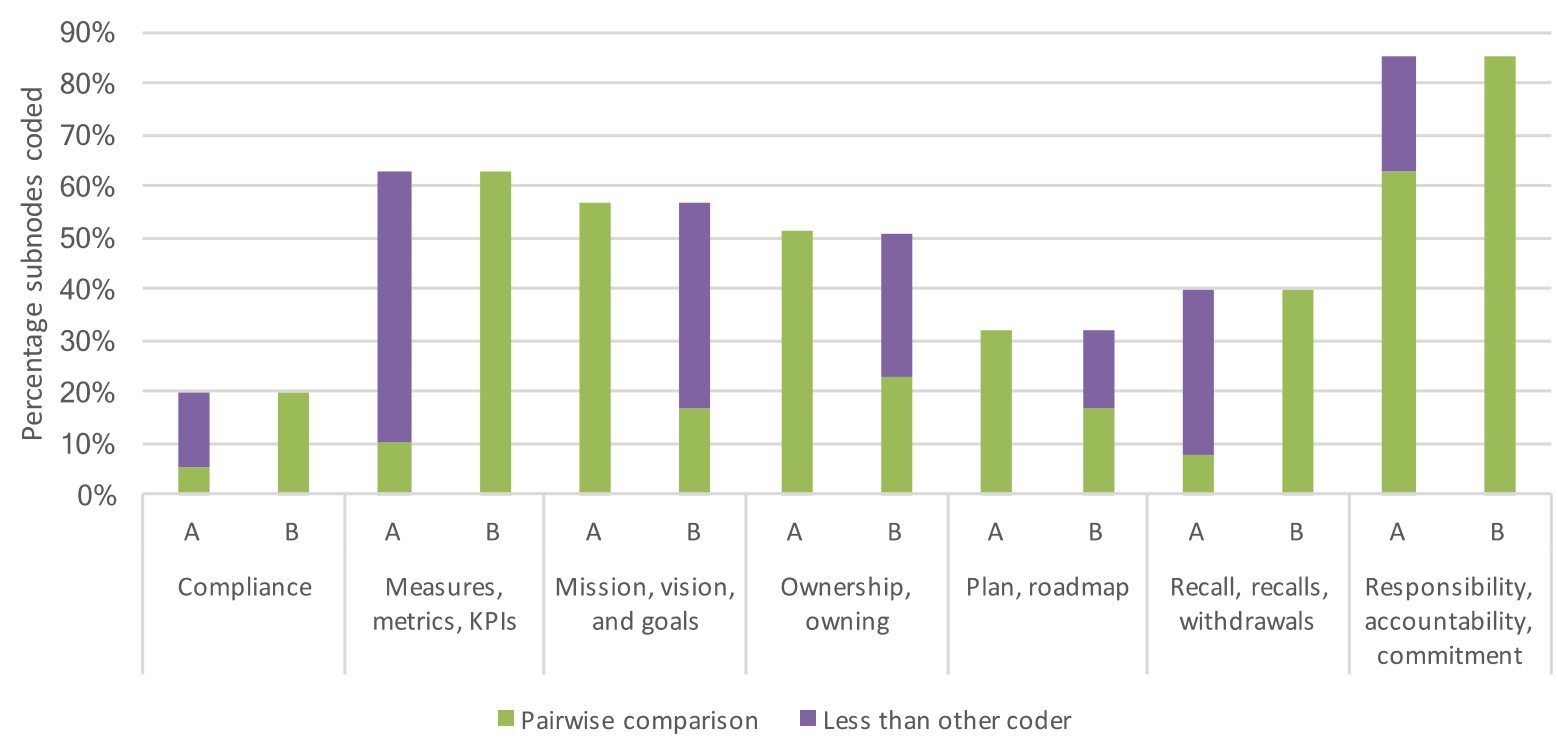

Figure 5: Values and Mission by sub-node and by coder ( $A$ and $B=$ two

For Risk Awareness (Figure 6), most of the difference comes from the sub-node "Risks

321 and Hazards." Coder A coded $29.75 \%$ more in this sub-node than coder B. In looking at the

322 verbatim, it shows that HACCP, risk assessment, contamination, foreign material, CCP, specific

323 foreign material findings, food security were examples of words and phrases being coded.

324 Generally, Coder A has more detailed word coding on hazards and risks and Coder B coded

325 specific bacteria references and risks and hazards more generally. 


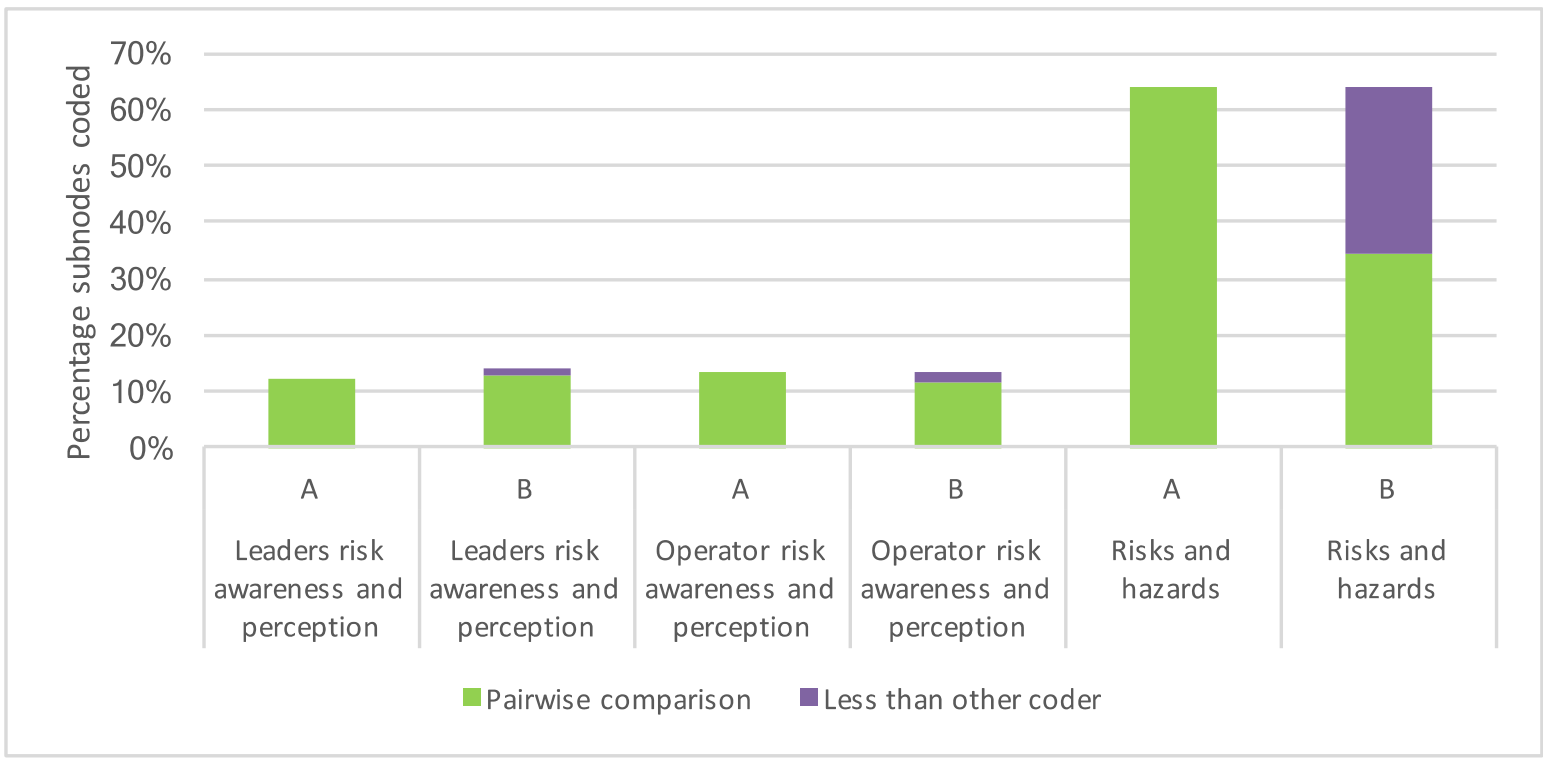

Figure 6: Risk by coder and sub-nodes ( $A$ and $B=$ two different coders).

\subsection{Coding Discrimination and Cluster Analysis}

To investigate if data from the coding framework and process can discriminate between

332 the food safety culture dimensions a cluster analysis of the coded sections of the verbatim

333 content was completed (Figure 7). The Pearson's coefficient shows values at or equal to 0.5 or

334 above for similar items and values less than of 0.5 or less for items distinctly different. The

335 distinctly different items were discussed by the coders and the coding framework was updated.

336 As such, eight major "stems' of similar word content were identified, (1) Rewards and

337 Celebration, (2) Technology and Data, (3) Risks and Hazards, (4) Actions/NCs, (5) Training,

338 education, learning proficiency (6) A group of items related to, vision, mission, values,

339 improvements, consequences, awareness, and ownership (7) Team, and (8) Pride and Recall. The

340 eight "stems" can be directly aligned to the five dimensions but also add more structure to the 
341 sub-nodes. This suggested dimensional framework (Figure 8) raises interesting questions that can

342 be useful in the assessment of maturity e.g., what is the connection between pride and recall?

343 What is driving similarity between leaders and employee risk awareness and change,

344 communication, and responsibility? The revised sub-nodes help get closer to some of the

345 manifest data in the texts analyzed. For example, original sub-node was worded as 'mission,

346 vison, and goals' this lead to significant discrepancy between coder A and B (figure 5). By

347 revising this sub-node to two sub-nodes 'direction' and 'goal' the coders were able to meet the

348 standard of $90 \%$ agreement and the content coded provided more clarity as for how the

349 organization set both direction and goals or not. In other words, more accuracy in coding by

350 individual coders was gained using these revised sub-nodes and this allowed not only better

351 consistency between the coders but also more detail to be identified from the data, thereby

352 adding to the overall analysis of an organizations food safety culture maturity. 
Figure 7: Nodes clustered by word similarity

Page $\mathbf{2 3}$ of $\mathbf{3 5}$ 


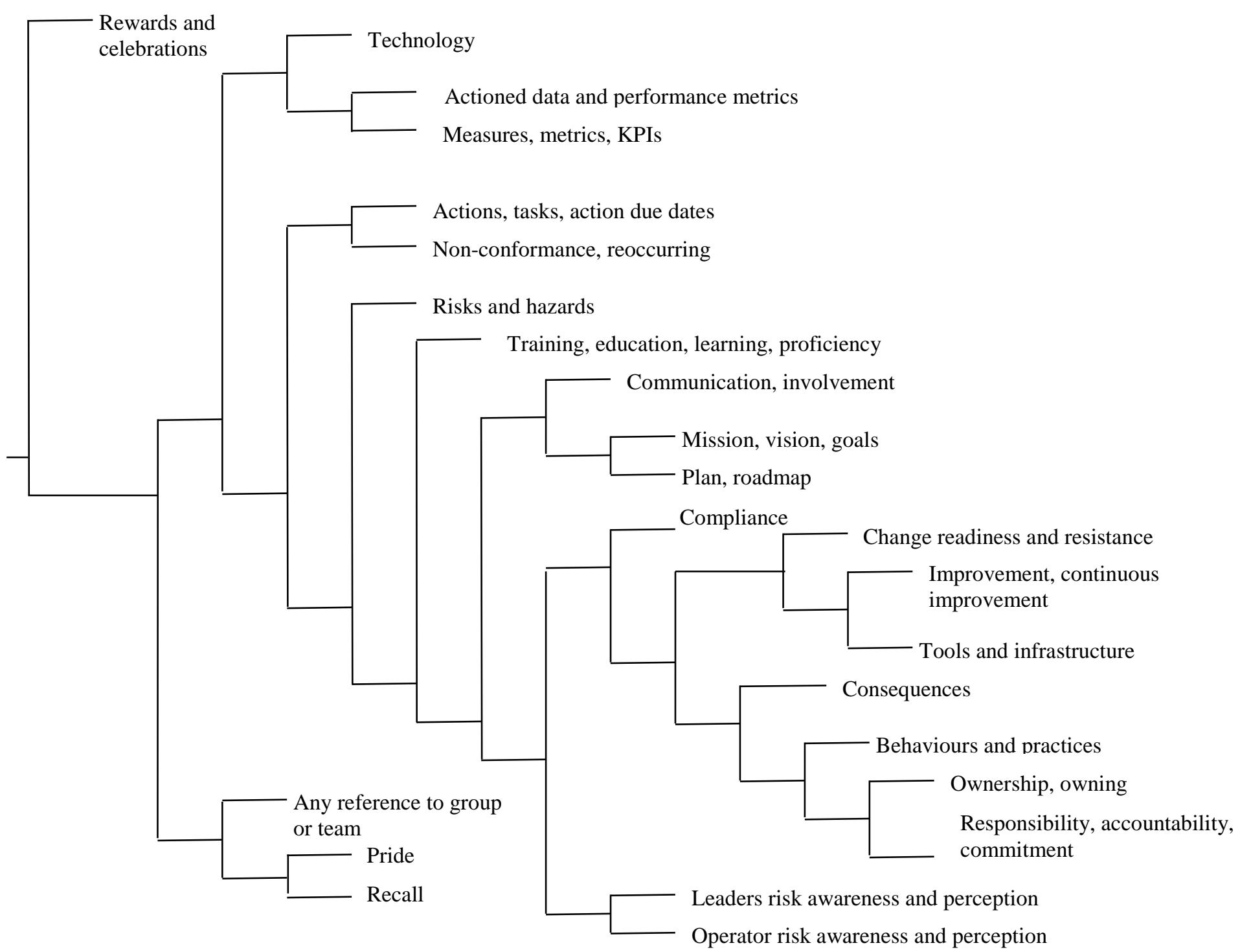

Page $\mathbf{2 4}$ of $\mathbf{3 5}$ 
355 Figure 8: Revised dimension framework and sub-nodes based on cluster analysis. Ledger: Red $(\mathbb{Q})=$ Vision and Mission,

356 Yellow $(\circlearrowleft)=$ People, Green $(\diamond)=$ Consistency, Blue $(\square)=$ Adaptability, and Purple $(\square)=$ Risks and Hazards. 


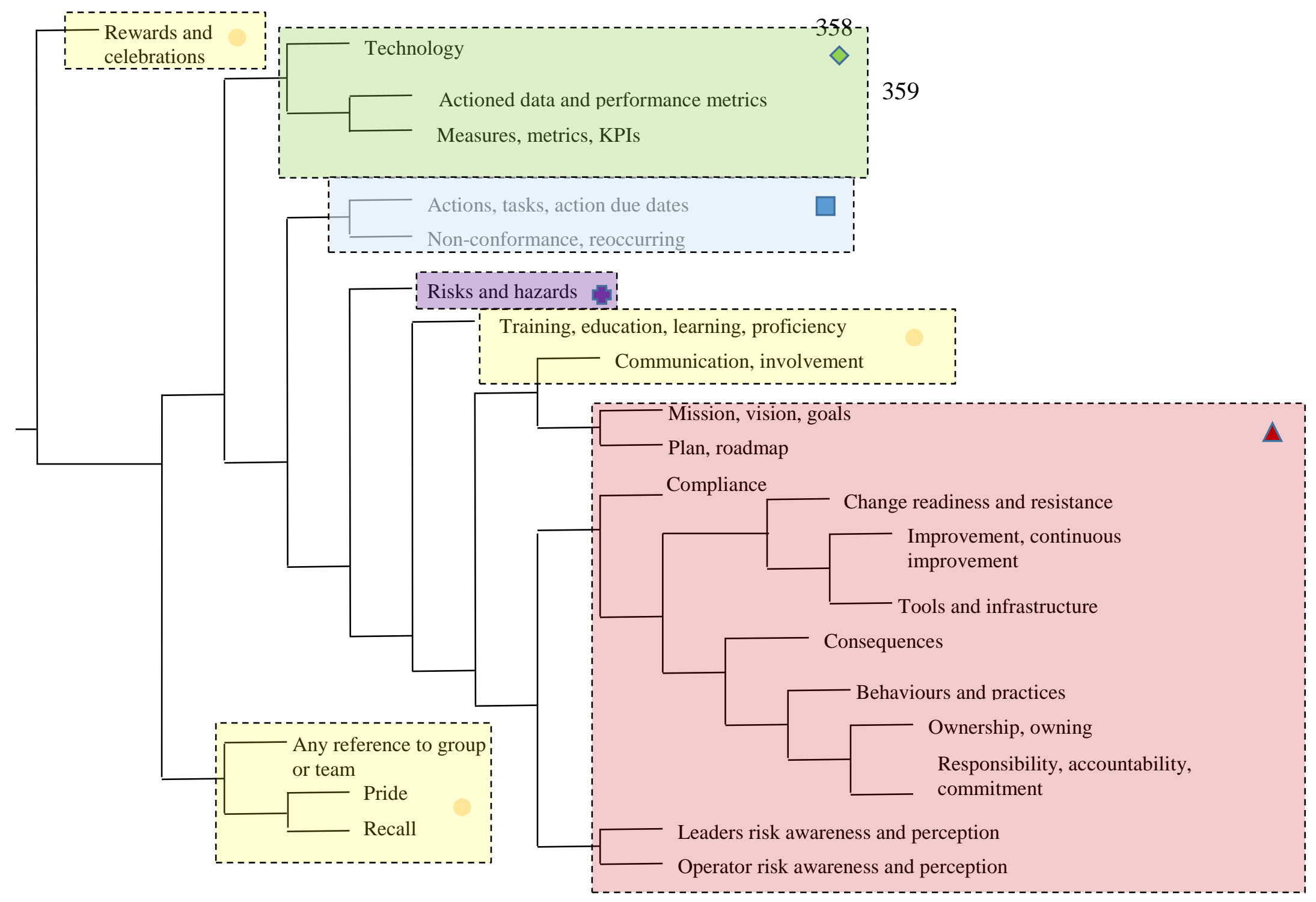

Page 26 of 35 


\subsection{Content Analysis comparison - performance documents and interviews}

362 A comparison of data from the performance documents and interview transcripts was

363 completed to investigate if method triangulation increases the validity and

364 quality/trustworthiness of food safety culture evaluation (Figure 9). Except for audit reports

365 which include reproduction of requirements from respective standards, performance documents,

366 mean word count ranges between 767 - 1,986 per document depending on document type

367 compared to interview transcripts mean word count between 4,601-7,369 per transcript

368 depending on function. Food safety and Quality interviews were generally longer than

369 Manufacturing. As such, it was to be expected that content of the interview transcripts was more

370 detailed and targeted for the purpose. The chart shows that more content was coded in the

371 interviews than in the performance documents except for the dimension "people systems." This

372 is interesting as most of the documents submitted for analysis were technical in nature e.g., audit

373 reports, meeting minutes, and inspection reports. Still these documents provide valuable data

374 related to people systems, specifically rewards and celebrations, teams, knowledge, and learning. 


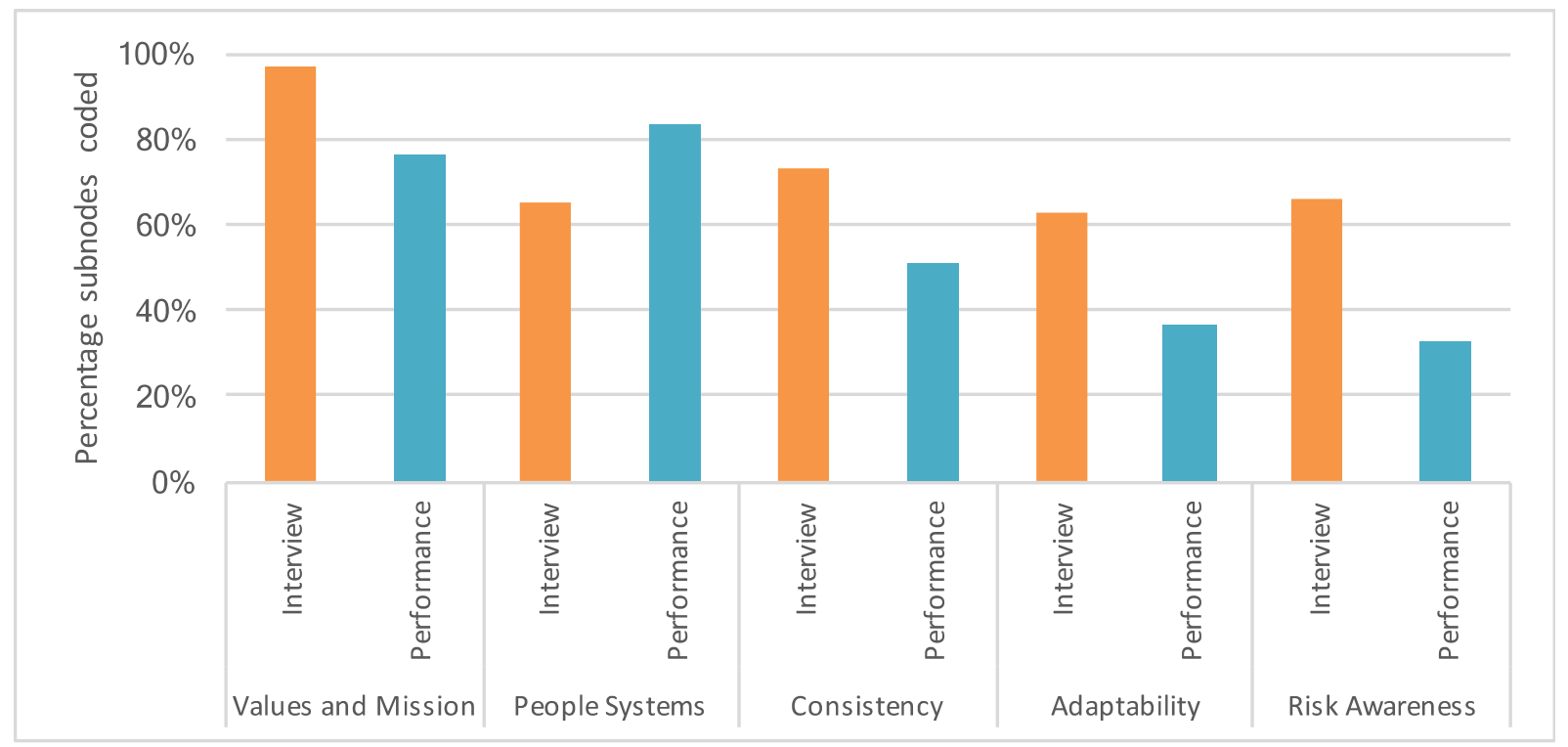

Figure 9: Coding by document type by dimension

\section{$378 \quad 3.5$ Plant discrimination - method triangulation.}

The triangulation analysis revealed a difference between and within plants. Based on the

380 coding consistency and discrimination it was concluded that the coding process is a valid method

381 for evaluating food safety culture. Based on this conclusion three scores per plant were plotted

382 on the maturity model (Figure 10). This shows some disparity both within and between plants.

383 The results for P2 and P5 have the least difference between methods. This means that the

384 individuals rating of food safety maturity, the documented performance, and what was said by

385 leaders in conversation are telling similar stories. In a reevaluation situation, it could be

386 considered to only apply one of the three methods to save time and effort. P3 shows the greatest

387 difference between methods. This means that individuals rate the plants food safety maturity

388 significantly higher than what was found in documented data and what was being said by 
389 leaders. In follow up, it would be important to schedule more interviews and focus groups to

390 better understand this difference as a scale does not provide a complete picture to help the plant

391 change. P1 and P4 have comparatively low scores for the documented performance compared

392 with their other measures and it might be interesting to look at the purpose of the submitted

393 documents and if there is an opportunity to better used these; however, what was evaluated by

394 the individual and said by leaders are relatively close, particularly in P1, P5 and, to a lesser

395 extent, P2. P1 is especially interesting as leaders appear to evaluate maturity directionally higher

396 than all employees. This reflects the findings in earlier study with a significant difference

397 between leaders and supervisor (Jespersen et al., 2016)

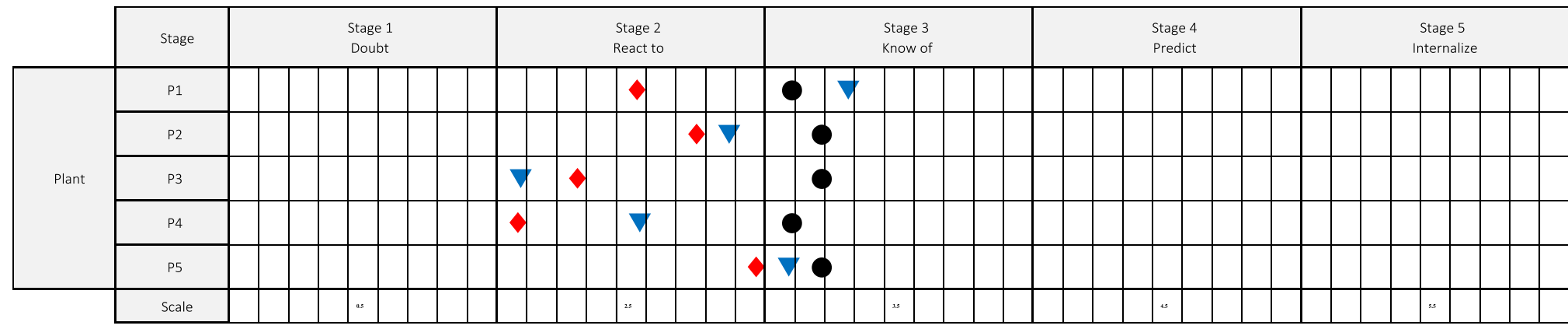

Figure 10: Plant Maturity - Plot of mean values as per method triangulation. Ledger: Dot $=$ Self-assessment scale result, Diamond - Performance document coding result, and Triangle $=$ Interview coding result.

\subsection{Discussion and conclusion}

The objective of this research was to develop and apply method triangulation to increase

405 validity of food safety culture evaluation results. Data from multiple sources were collected and

406 evaluation results from each plotted on a food safety culture maturity model. Data were analyzed 
407 for inter-coder and construct validity, and capability of discrimination within a food safety

408 culture maturity profiling system. Results from analysis of data from three methods, self-

409 assessment scale, document content analysis, and semi-structured interviews, were aggregated

410 and plotted on a food safety culture maturity scale. The dispersion between the mean results per

411 method per plant confirms the need to apply triangulation to get an accurate and trustworthy

412 evaluation of food safety culture. With use of just one of the methods applied in this research the

413 stage of maturity would have been evaluated either too low or too high and subsequent tactical

414 interventions would not have been as effective as intended. For example, a learning program for

415 frontline supervisors in stage 2 "reactive" is largely about creating a personal connection to build

416 a strong foundation of "why food safety is important to you?" A program in stage 3 "knowing" is

417 mostly about increasing cognitive capacity for solving problems, finding root causes, and

418 removing issues permanently. These are two very different objectives that, if applied to the

419 wrong stage, would likely fail and be seen as not valuable to business results. The results showed

420 that mean maturity for all plants was generally higher when assessed through the self-assessment

421 scale ranging from $3.06-3.18$. The results from the semi-structured interviews were closer to

422 the self-assessment scale for two plants and lower than the self-assessment scores for the other

423 three plants. It was also found that results from the food safety and quality leader interviews

424 generally rated maturity higher than that for manufacturing leaders. The findings from the two

425 functions were found to be significantly different both in maturity assessments and amount of

426 textual data. Mean maturity scores derived from the textual data were the lowest of the three

427 measures except for one plant. In general, more action content (e.g., tasks, follow up) was 
428 captured in the textual data and this was to be expected given the original purposes of the 429 documents e.g., meeting minutes and inspection reports.

430 A coding framework was applied to derive data via content and textual analysis. The

431 framework was consistently applied by two researchers within $90 \%$ agreement except for two

432 dimensions; Values and Mission and Risks and Hazards. This difference called for clarification

433 and better definition of the sub-nodes e.g., "mission" this sub-node is better defined as

434 "direction" and can include content related to mission, vision, strategies and generally where a

435 specific direction for food safety is documented. In the Risks and Hazards dimension it was

436 found that one coder coded very specific words e.g., hazards, CCP. It is worth noting that this

437 coder has a long and detailed background in defining hazard and risk management strategies and

438 was likely influenced by this in the coding. This underlines the importance of the iterative coding

439 process with the two checks for consistency; however, it also questions if Risks and Hazards is,

440 in fact, a stand-alone dimension. Is content related to "hazards" and "CCPs" relevant for

441 evaluating culture? Because of this issue and the fact that only two systems (De Boeck et al.,

442 2017; Wright, 2013) have separated out Risks as a stand-alone dimension (Jespersen, Griffith,

443 and Wallace, 2017), it is worth discussing if this dimension should remain in the food safety

444 culture theoretical framework (Figure 1) or if is best considered in the evaluation of food safety

445 management systems.

446 This study was conducted as part of a larger study with 21 plants but this analysis was

447 completed with data from a sub-set of five. This was done both to ensure that there was enough

448 time to execute the coding process fully on 10 interview transcripts and 20 performance 
449 documents by two researchers and to analyze a sufficiently large sample for triangulation

450 purposes. It is recommended that more work is done with more researchers to promulgate

451 content analysis as a method for evaluating both food safety performance and food safety culture

452 maturity. It was unexpected that such similarity would be found in the five plants, where

453 performance ranged from stage 2 maturity "reactive" to stage 3 "know" (Jespersen \& Edwards,

454 Under review; Jespersen et al., 2016) or all plants and documents. This could be due to the

455 geographical dispersion of the plants, this subset all being in North America, and therefor under

456 similar North American legal systems and customer expectations. It could also be a case of

457 selection bias as the participating companies were not gathered via randomization or quasi-

458 random assignment, rather through senior leader interest and board willingness to participate in

459 the research. In this research, selection would be present if those who participated in the study

460 and responded to the survey are those that have internalized the importance of culture and/or

461 those that engage in "cheap talk" about culture. It is reasonable to assume some sampling bias

462 due to the voluntary nature of the participants.

463 In summary, the research adds information and knowledge, derived through a transparent

464 and rigorous process, to the food safety culture domain. Specifically, it adds proof that reliance

465 on a single method for evaluation food safety culture can give inaccurate results and should be

466 treated with caution. This has practical significance for companies who invest, not just in such

467 results, but in subsequent improvement tactics. 
The authors wish to thank representatives from the five companies who participated in

the study. For taking the time to provide data and guidance in this important endeavor.

\section{References}

Ball, B., Wilcock, A., \& Aung, M. (2009). Factors influencing workers to follow food safety management systems in meat plants in Ontario, Canada. International journal of environmental health research, 19(3), 201-218. doi:10.1080/09603120802527646

Bauwens, A. (2010). The Use of Method Triangulation in Probation Research. European Journal of Probation, 2(2), 39-52. doi:doi:10.1177/206622031000200204

Berg, B. L., Howard. (2012). Qualitative Research Methods for the Social Sciences (Vol. 8th): Pearson Education Inc.

Brinkmann, S. K., Steinar. (2015). InterViews: learning the craft of qualitative research interviewing: Sage Publications.

Campbell, D. a. F., D. . (1959). Convergent and discriminant validation by the multitrait - multi method matrix. Psychological bulletin, 56, 81-105.

Carugi, C. (2016). Experiences with systematic triangulation at the Global Environment Facility. Evaluation and Program Planning, 55, 55-66. doi:http://dx.doi.org/10.1016/j.evalprogplan.2015.12.001

Creswell, J. W. (1998). Qualitative Inquiry and Research Design : Choosing Among Five Traditions. Thousand Oaks, Calif: Sage Publications.

De Boeck, E., Jacxsens, L., Bollaerts, M., Uyttendaele, M., \& Vlerick, P. (2016). Interplay between food safety climate, food safety management system and microbiological hygiene in farm butcheries and affiliated butcher shops. Food Control, 65, 78-91. doi:http://dx.doi.org/10.1016/j.foodcont.2016.01.014

De Boeck, E., Jacxsens, L., Bollaerts, M., \& Vlerick, P. (2015). Food safety climate in food processing organizations: Development and validation of a self-assessment tool. Trends in Food Science \& Technology, 46(2, Part A), 242-251. doi:http://dx.doi.org/10.1016/j.tifs.2015.09.006

De Boeck, E., Mortier, A. V., Jacxsens, L., Dequidt, L., \& Vlerick, P. (2017). Towards an extended food safety culture model: Studying the moderating role of burnout and jobstress, the mediating role of food safety knowledge and motivation in the relation between food safety climate and food safety behavior. Trends in Food Science \& Technology, 1-13.

Denison, D., Hooijberg, R., Lane, N., \& Lief, C. (2012). Leading Culture Change in Global Organizations: Aligning Culture and Strategy. John Wiley \& Sons.

Denison, D. R. (1997). Corporate Culture and Organizational Effectiveness (Vol. 2nd edition (May 1997)): Aviat.

Denison, D. R., \& Mishra, A. K. (1995). Toward a Theory of Organizational Culture and Effectiveness. Organization Science, 6(2), 204-223.

Denzin, N. K. (1970). The Research Act: A Theoretical Introduction to Sociological Methods: Transaction.

Denzin, N. K. (2012). Triangulation 2.0. Journal of Mixed Methods Research, 6(2), 80-88. doi:10.1177/1558689812437186 
Denzin, N. K., \& Lincoln, Y. S. (2011). The Sage handbook of qualitative research (4th ed.).

Floyd, J. (1993). The use of across-method triangulation in the study of sleep concerns in healthy older adults. ANS Adv Nurs Sci., December(16), 70-80.

Guldenmund, F. W. (2000). The nature of safety culture: a review of theory and research. Safety Science, 34(1-3), 215-257. doi:http://dx.doi.org/10.1016/S0925-7535(00)00014-X

Hofstede, G. (1980). Culture's Consequences - International differences in work-related values. : Sage Publications, London.

Hofstede, G. (2001). Culture's Consequences - Comparing Values, Behaviours, Institutions and Organizations Across Nations: Thousand Oaks, Sage Publications.

Hofstede, G. (2013). Values Survey Module 2013, Manual and VSM Questionnaire - English Version. Retrieved from http://geerthofstede.com/research-and-vsm/vsm-2013/

Holstein, J. A. G., J. F. (1995). Qualitative Research Methods: The active interview: SAGE Publications Ltd.

Jespersen, L., \& Edwards, A. M. (Under review). Predictive Attributes of Food Safety Culture and Climate. Food Research International.

Jespersen, L., Griffiths, M., Maclaurin, T., Chapman, B., \& Wallace, C. A. (2016). Measurement of food safety culture using survey and maturity profiling tools. Food Control, 66, 174-182. doi:http://dx.doi.org/10.1016/i.foodcont.2016.01.030

Jespersen, L., T., M., \& Vlerick, P. (2017). Development and validation of a scale to capture social desirability in food safety culture. Food Control.

Kopinak, J. K. (1999). The Use of Triangulation in a Study of Refugee Well-Being. Quality and Quantity, 33(2), 169-183. doi:10.1023/a:1026447822732

Lombard, M., Snyder-Duch, J., \& Bracken, C. C. (2002). Content Analysis in Mass Communication: Assessment and Reporting of Intercoder Reliability. Human Communication Research, 28(4), 587-604. doi:10.1111/j.1468-2958.2002.tb00826.x

Miles, M. B. H., A.M. (1994). Qualitative data analysis: an expanded sourcebook (2nd ed.): Thousand Oaks: Sage Publications.

Neuendorf, K. A. (2002). The content analysis guidebook: Thousand Oaks : Sage Publications.

Robson, C. (2011). Real world research : a resource for users of social research methods in applied settings. Chichester, West Sussex: Chichester, West Sussex : Wiley.

Schein, E. H., \& Schein, P. (2017). Organizational Culture and Leadership: Wiley.

Srinivasan, A., \& Kurey, B. (2014). Creating a Culture of Quality. Harvard Business Review, 92(4), 23 25.

Taylor, J., Garat, J. P., Simreen, S., \& Sarieddine, G. (2015). An industry perspective: A new model of Food Safety Culture Excellence and the impact of audit on food safety standards. Worldwide Hospitality and Tourism Themes, 7(1), 78-89. Retrieved from http://sfx.scholarsportal.info/guelph/docview/1648846697? accountid=11233.

Wallace, C. A. (2009). The impact of personnel, training, culture and organisational factors on the application of the HACCP system for food safety management in a multinational organisation, . (PhD Thesis).

Wilcock, A., Ball, B., \& Fajumo, A. (2011). Effective implementation of food safety initiatives: Managers', food safety coordinators' and production workers' perspectives. Food Control, 22(1), 27-33. doi:10.1016/j.foodcont.2010.06.005

Wright, M. (2013). A tool to diagnose culture in food business operators, Food Standards Agency Research Report.

Yeasmin, S., \& Rahman, K. F. (2012). 'Triangulation' Research Method as the Tool of Socical Science Research. BUP Journal, 1(1), 154-163. 
Page $\mathbf{3 5}$ of $\mathbf{3 5}$ 